www.ejop.org

\title{
Psychosocial Impact of Mobile Telework: Results from an Online Survey
}

\author{
Hiltraut Paridon \\ BGAG - Institut Arbeit und Gesundheit, \\ Dresden, Germany \\ Marlen Hupke \\ Institut für Arbeitsphysiologie an der Universität Dortmund, \\ Dortmund, Germany
}

\begin{abstract}
The present study mainly investigates the psychological strain of mobile workers who use information and communication technology. Data was collected via an onlinequestionnaire. More than 200 participants took part. The results show that the ergonomic conditions of mobile workers should be improved. Flexibility and decision-making latitude associated with mobile work are evaluated quite positively. Constant availability and blurring of boundaries between work and private life is assessed as negative by only one third of the participants. The majority of the respondents receive support from colleagues and experience social interaction. As found in other areas of work, some of the psychological factors may be a risk as well as a resource depending on their extent and duration. This applies, for example, to flexibility and self-organisation. Further research is needed to ascertain to which degree such factors are appropriate for health and wellbeing. Furthermore, future research should differentiate between different kinds of mobile work, namely whether it is office-based or industrial.
\end{abstract}

Key words: mobile telework, psychosocial strain, online survey

\footnotetext{
1 This communication is based on a literature analysis carried out in the framework of a contract financed by the European Commission (Tender Nr. VT/2007/0117 - Study contract VC/2008/0002 for the Investigation into the impact on occupational safety and health in Europe of the increasing use of portable computing and communication devices). The views expressed in this communication are those of BGAG and do not necessarily reflect a Commission's official position.
} 
Introduction

Working mobile is becoming a necessary part of work for more and more people. It can be defined as work involving operations at several locations and travelling between them (Hurme, 2005). In 2002, 28.4\% of workers in the European Union spent at least part of their work being mobile (SIBIS, 2002/2003). The need for mobile technological support associated with this development has resulted in the fast development of technical devices enabling workers to access important information when working away from company premises. People using mobile technical devices for their work are referred to as mobile teleworkers (Garrett \& Danziger, 2007) mobile eWorkers (Gareis, Lilischkis \& Mentrup, 2006), virtual office workers (Hill, Ferris \& Märtinson, 2003) or mobile ICT-supported (information and communication technology) workers (Kohn, 2006). The terminology differs among studies and slight differences may be observed (Hill, Ferris \& Märtinson, 2003). Whilst studies on mobile telework, for example, often refer to knowledge workers and include a necessary amount of time spent working mobile (generally more than 10 hours, European Commission, 2001) mobile ICT-supported work refers to a larger range of mobile jobs including workers such as drivers or service engineers and lacks the focus on time limits (Kohn, 2006). According to the studies mentioned the terminology will also differ in this article but mainly concentrate on the term of "mobile ICT-supported workers".

The proportion of such mobile ICT-supported workers among overall EU15 employment grew from 1.5\% to 4\% in the period 1999 to 2002 (Gareis, Lilischkis \& Mentrup, 2006). Reasons for this increase can mainly be attributed to globalization. It creates the need to travel between different branches of a company or its customers and work during these times of travel. Another reason arising from increasing global competition may be the need to offer services close to the customer which require high amounts of flexibility, availability and mobility. A very important reason is, of course, technical development itself which has enabled workers to be mobile without being totally cut off from communicating with the company.

Research on the psychosocial risks and resources associated with mobile ICTsupported work which include organisational as well as personal factors is scarce and a fuller theoretical or empirical development of the topic has been neglected so far (Hislop \& Axtell, 2007, Hill et al., 2001). To complement the limited existing data, research results from the closely related forms of mobile work and home-based telework have to be considered in order to provide a general overview of the topic. Home-based telework has been investigated thoroughly and has provided the most results (Hill, Ferris \& Märtinson, 2003). Accordingly, the following overview shall intro- 
duce readers to research results pertaining to the most important psychosocial risks and resources of mobile ICT-supported work and to other related forms of work that may be applied to ICT-supported work.

Flexibility and Autonomy

In general, mobile workers have more control over their own actions because only few possibilities exist for direct supervision by the company. A study by Hill et al. (1998), for example, found significant positive relations between work in virtual offices and flexibility. Mobile workers can choose when to complete tasks, may arrange appointments and take breaks when they want. Such autonomy has been found to correlate positively with job satisfaction and the reduction of turnover intent and role stress (Gajendran \& Harrison, 2007). However, such flexibility can not only be assessed as positive. Mobile ICT-supported workers have to be very flexible in changing work locations within short time periods and face a blurring of boundaries with their private life. Much depends on how the working conditions are agreed on between employees and supervisors (European Agency for Safety and Health at Work, 2007). When the employee has to be available at all times and can not arrange appointments and working times in accordance with their own preferences, advantages of flexibility can vanish quickly. This forced flexibility can lead to impairments in physical and mental health while freely-chosen flexibility can contribute positively to health (European Agency for Safety and Health at Work, 2007).

Negative effects of work flexibility are also reported by Goudswaard and de Nanteuil (2000) who found that flexible working strategies lead to a loss of control over working time and to reduced opportunities for recreation. Martens et al. (1999) showed that flexible work schedules were positively correlated with health complaints and a general decrease in well-being. Although flexibility to arrange working times may be evaluated very positively by some employees it also has to be considered that many people prefer regular working times that ensure they can fulfil their private commitments at fixed times every day (European Foundation for the Improvement of Living Conditions, 2007).

Social Support and Isolation

Mobile ICT-supported workers often work away from the company premises and from their colleagues and supervisors regardless of whether they are managers, sales representatives or drivers. Whilst for home-based teleworkers this implies the advantage of facing less disturbances and distractions from others; for mobile ICT- 
supported workers this advantage is smaller as disturbances arise from other sources when working in trains, airports or in other public places.

Working away from the company premises means having fewer opportunities to seek support from colleagues and supervisors. Social support has been found to serve as a buffer in the relationship between work-related stress and the development of mental and physical disease (Karasek \& Theorell, 1990, Dormann \& Zapf, 1999 ), so a lack of such support might result in a higher susceptibility to illness. Mulki et al. (2008) report results from a study amongst salespeople who felt a loss of camaraderie, felt left out of company affairs and felt they had less career support and fewer chances to be involved in major projects at work. These results are confirmed by Mann and Holdsworth (2003) who found that $67 \%$ of home-based teleworkers said they feel lonely at least sometimes. A study on mobile workers also found that these employees report higher feelings of job insecurity (Brandt \& Brandl, 2008).

In contrast to these findings the study by Gajendran and Harrison (2007) found no negative consequences of work away from the company in general and even positive effects on the relationship between the mobile working employee and their supervisor.

\section{Supervision}

Supervising mobile-working employees differs from the supervision of employees in the office. Neither adherence to working time and breaks nor working style can be directly observed.

Under these conditions trust between the employee and the supervisor is very important (Mulki et al., 2008). To create and maintain such a trustful relationship, regular opportunities for communication and exchange should be introduced. According to Mulki et al. supervisors should also help mobile working employees to structure their work and prepare them to self-organize tasks. To increase self-organization skills, training might be offered to the mobile-working employees.

As the achievements of mobile working employees are difficult to evaluate Illegems, Verbeke and S' Jegers (2001) as well as Hörmann (2000) propose the introduction of management through objectives or goals. These goals or objectives should be discussed in regular meetings. Supervisors should also give special attention to offering feedback and rewards to their mobile workers as opportunities may be significantly fewer than with office-based workers and give the employee a feeling of not really 
belonging to the company or not being appreciated. An imbalance between reward and effort perceived by the employee may be a source of stress and poor mental health (Siegrist, 1996).

\section{Work-Life Balance}

According to a study by Hill, Ferris and Märtinson (2003) on different kinds of work settings, work in virtual offices was negatively correlated with work-life balance and personal-family success. This may be explained by the blurring of boundaries between work and family life as these workers are well equipped with mobile computing and communication devices and are therefore permanently on call and able to work; even when at home. As virtual office work partly takes place at home, the lack of physical boundaries between work and private life may also impact negatively on family life.

A study by Hislop and Axtell (2007) showed that the effects of work on family life depend greatly on the kind of mobility the mobile teleworker faces in their job. While low discretion workers such as drivers or service engineers travel smaller distances and remain local, mobile teleworkers with high discretion often travel large distances and have to stay away from home overnight. Thus, negative effects on work-life balance have been found for high discretion workers whereas for low discretion workers there were no such effects.

Brandt and Brandl (2008) found in a study among 512 mobile-working and 1,194 company-based employees that mobile workers perceived the incompatibility of work and family as one of the most negative aspects of their work.

\section{Personal Characteristics}

As mobile ICT-supported workers mainly work alone and have to structure and organize their work on their own, the ability to self-organize seems to be a very important requirement when employees are intended to start working mobile. Hörmann (2000) also points to the fact that employees have to be well prepared regarding what to expect and well qualified for the demands placed upon them.

In addition to personal characteristics, demographic factors such as age or gender may also be risk factors of mobile ICT-supported work. Although according to Haddon and Brynin (2005) most workers using mobile ICT are men it can be assumed that there is no particular reason why women should be at higher or lower risk when work- 
ing under such conditions. The reason for this lower mobility is probably attributable to the nature of typically "female" jobs and the fact that responsibility for childcare often still falls to women (Burchell et al., 2007). Additionally elderly people do not face particularly high risk rates when working in mobile ICT-supported jobs. It should be taken into consideration that they are often not so familiar with technical devices and may need more time to become familiar with them (Charness, 2006), but at the same time with their experience they are more independent of their colleagues and supervisors and may work more independently (European Agency for Safety and Health at Work, 2007).

Whilst the factors named may be some of the most important arising from mobile ICT-supported work there are many more that can be considered as risks or resources of mental and also physical health. Some of these factors, such as the ones already mentioned in detail, may be resources at a certain intensity and design but develop into risk factors at other intensity levels. Factors that may also play a role are, for example, changes in working time, communication barriers in mobile ICT, reduced access to company networks and informal information, and work place insecurity.

All of the aforementioned factors can lead to mental and also physical strain. The psychosocial consequences of the named stressors are mostly discussed in the frame of stress theory. If these factors impact on the employees for a long time, consequences such as burnout, cardiovascular diseases (Öhlin et al, 2004), psychosomatic disorders or impairment of the immune system (Jones \& Bright, 2001) may result and lead to low productivity, poor motivation and absenteeism.

\section{Methodology}

Data were collected via an online questionnaire. It included questions regarding:

- Use of mobile devices (7 questions)

- Ergonomic aspects (including software ergonomics if special software was used, 18 questions)

- Physical complaints (7 questions)

- Psychological stress (23 questions)

For the questions about psychological stress the participants were asked to indicate in each case whether, and if so how frequently, the stressor impacts them (from "never" to "always"). Additionally they were asked to rate the respective situations. The following responses were possible:

- I think it's good. 
- I think it's neither good nor bad.

- I think it's bad.

- I have no opinion.

The formulation of the questions and the responses followed the format of the questionnaire "Psychological evaluation of working conditions screening for occupants of workplaces - (BASA)" (Richter, G., \& Schatte, M., 2005). Information about the survey and an invitation to take part in it were published in different newsletters and on the website of the German Social Accident Insurance (DGUV). Average duration to complete the questionnaire was 12.8 minutes.

\section{Participants}

219 people answered the questions. There were participants from all industries, but there were only very few people from some areas such as mining, gas, heating and water. The fields of "trade and administration" as well as "health service" were most strongly represented. The youngest participant was 20 and the oldest 71 years old. The average age was 43.5 years (standard deviation 10.1). The majority of the respondents were between 36 and 50 years old. $22.4 \%$ of the participants were women and $75.3 \%$ men. The respondents are on the road on average 4.2 days per week and on these days work 4.5 hours with IT devices. The respondents have on average approximately 15 telephone calls and 30 emails per day. The number of daily emails and daily telephone calls correlates significantly with .512 $(p<.01)$.

\section{Results}

The results will focus on psychological aspects but the other topics of the survey will also be briefly presented.

Used devices, ergonomic and health aspects

Almost all respondents work with a laptop (93.2\%). Similarly a large proportion of respondents use a mobile phone (81.7\%). A personal digital assistant (PDA) was used by a third and just on $10 \%$ used a Blackberry. Other devices which are used include navigation systems and smartphones. The evaluation of ergonomic aspects related only to situations in which IT devices were used. Almost $80 \%$ of respondents must sometimes adopt an uncomfortable position to use the devices. A mere $18 \%$ of respondents always have sufficient leg and foot room to change position. $45 \%$ of respondents reported that they can often or always adjust their seats. Almost $20 \%$ of 
respondents never have this possibility. Only $20 \%$ of respondents said that their chairs always or often had adjustable armrests. Over $40 \%$ of respondents can never adjust the armrests to a suitable height. There is significant improvement potential with regards to ergonomic conditions.

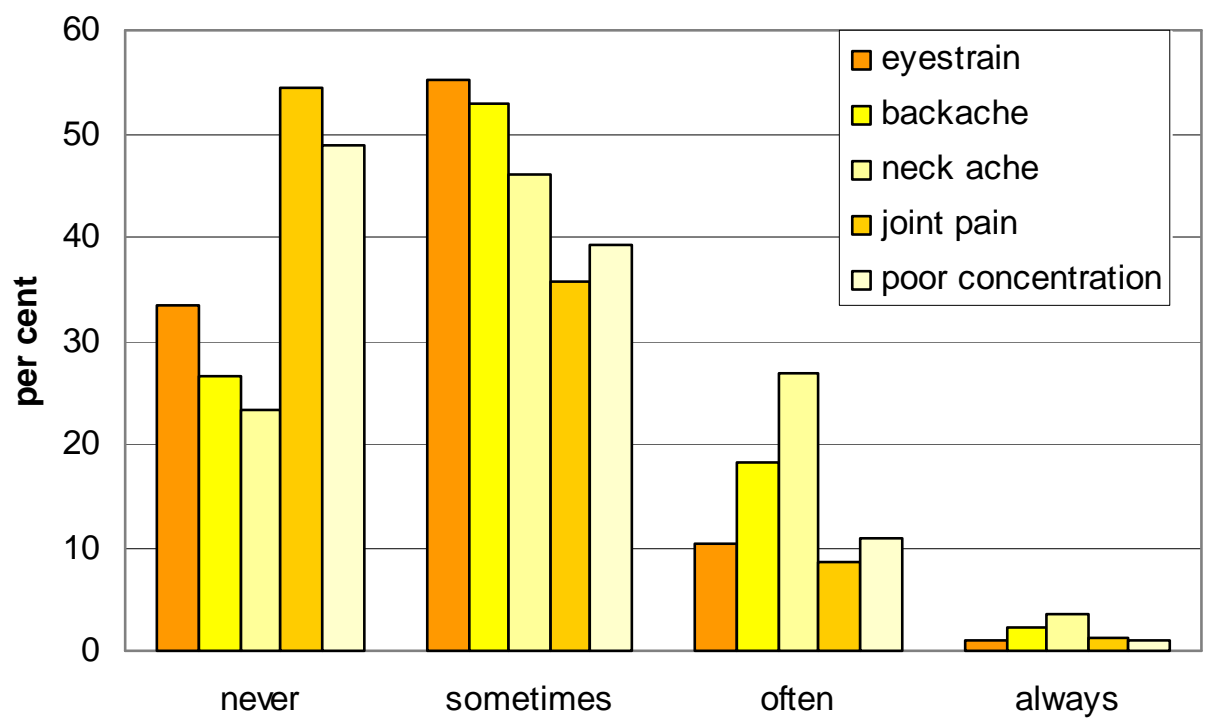

Figure 1: Frequency of physical complaints.

Figure 1 shows the frequency of physical complaints. Analyses show that there is no significant difference regarding the frequency of physical complaints dependent on whether the respondents:

- use few or many devices

- receive few or many emails

- conduct few or many telephone calls

- are younger or older.

Almost half of the respondents attribute their complaints to working with mobile IT devices. In order to reduce physical complaints stronger counter measures should be adopted.

\section{Work organisation}

With regards to work organisation the results show that $77 \%$ of respondents can often or always organize working time flexibly. High levels of flexibility are evaluated positively while low levels receive positive evaluations less often. $95 \%$ of respondents have sometimes, often or always a high degree of control over their own actions and decisions (figure 2.) $90 \%$ and $95 \%$ respectively of those who often or always have a high degree of action and decision-making scope think this is good. However, there are also those who never operate with much room for self-determination who also rate this as good. 


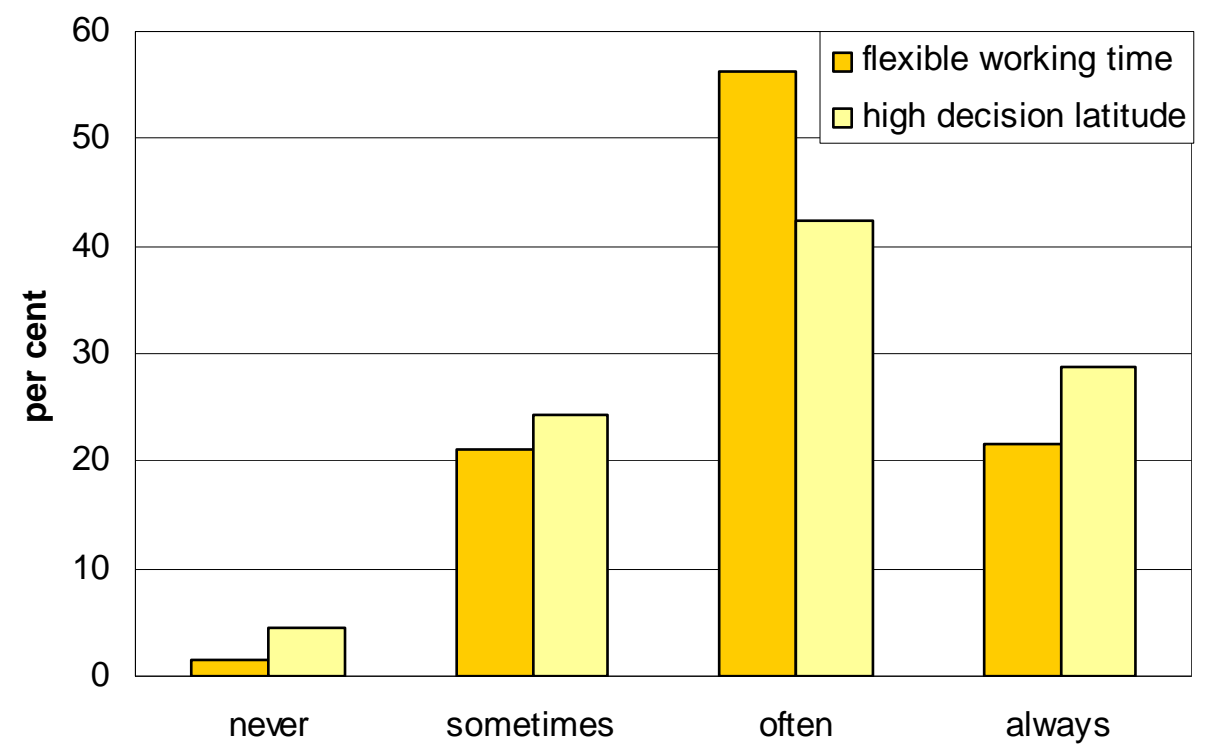

Figure 2: Frequency of how often participants have high flexibility in working time arrangements and high decision-making latitude.

The results also show that there are communication barriers. Only $12 \%$ of the participants feel that they always get all information that is relevant to their work. About 40 $\%$ are sometimes or often well informed. As expected the more that important information was available, the more positive the situation was rated.

$55 \%$ of mobile workers in this study said they never or only sometimes face blurring of boundaries between work and private life (figure 3). Of those who never experience the boundaries blurring $85 \%$ rated the situation as positive. Of the others about a third rated the situation as bad.

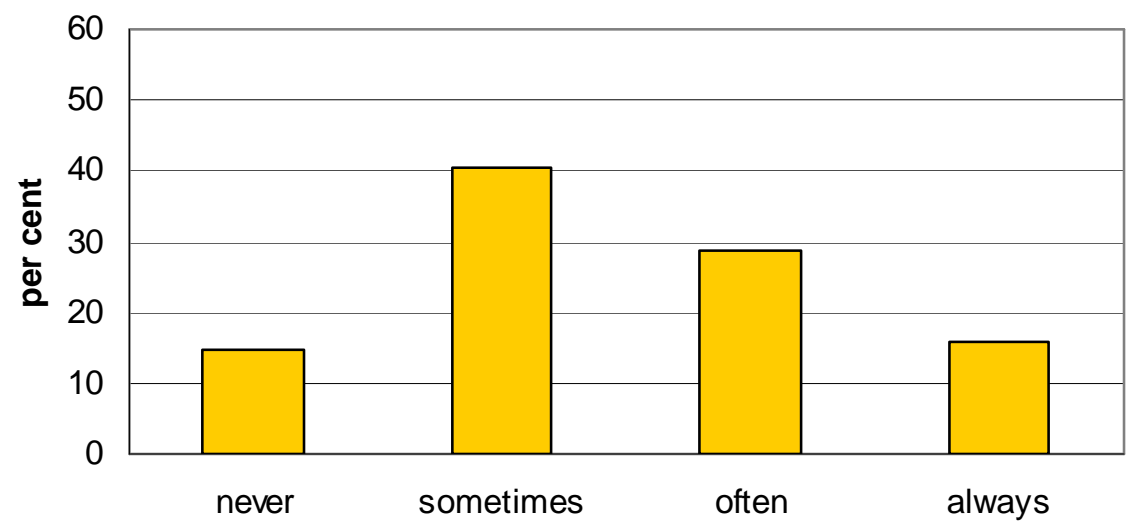

Figure 3: Frequency of how often participants experience a blurring of boundaries between work and private life. 
$60 \%$ of mobile workers reported that they always or at least often have to be available (figure 4) . 30 and $20 \%$ of people respectively think this is bad.

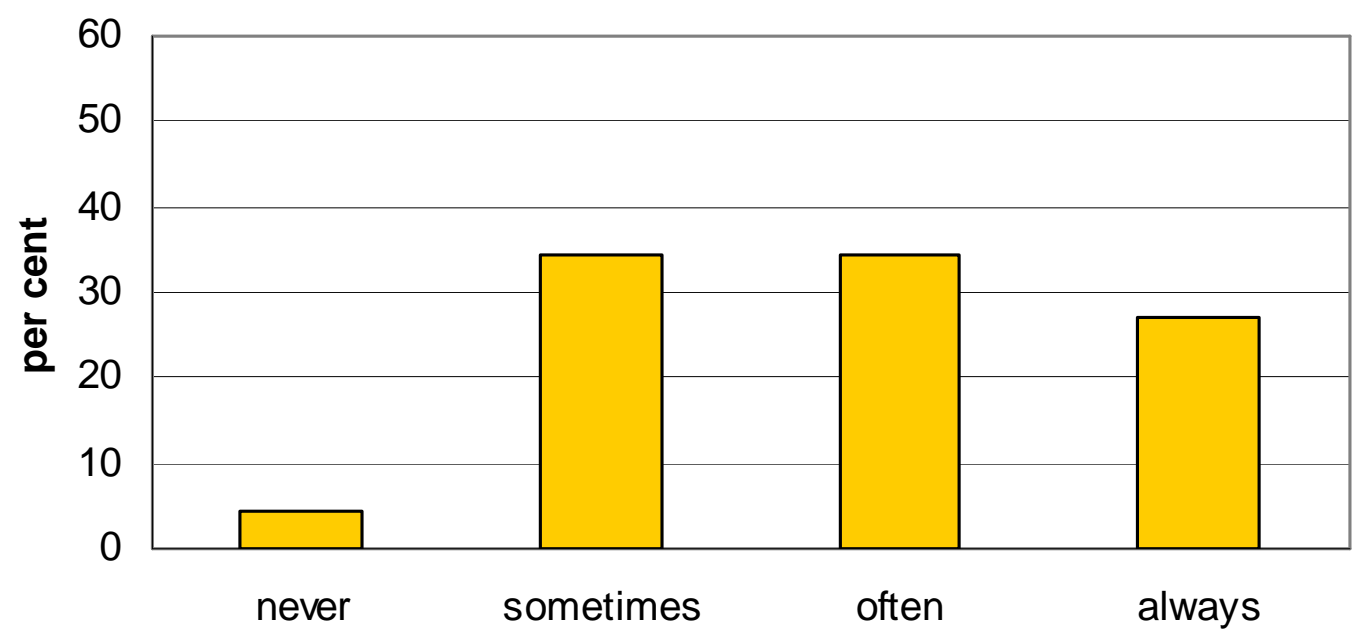

Figure 4: Frequency of how often participants always have to be available.

As expected, the more often there are interruptions due to telephone calls, colleagues or superiors, the more this is rated as bad. Interruptions due to emails are rated as negative less often. Only $26 \%$ of respondents can often or always complete tasks without being interrupted. There is no surprise here that the situation is rated positively when tasks can be completed without interruption.

Social relations at work

Virtually all participants have possibilities for social interaction and receive social support from colleagues during their work and evaluate these opportunities positively (figure 5). The situation here is also more positively rated when there are opportunities for social contact or when support is regularly received. 


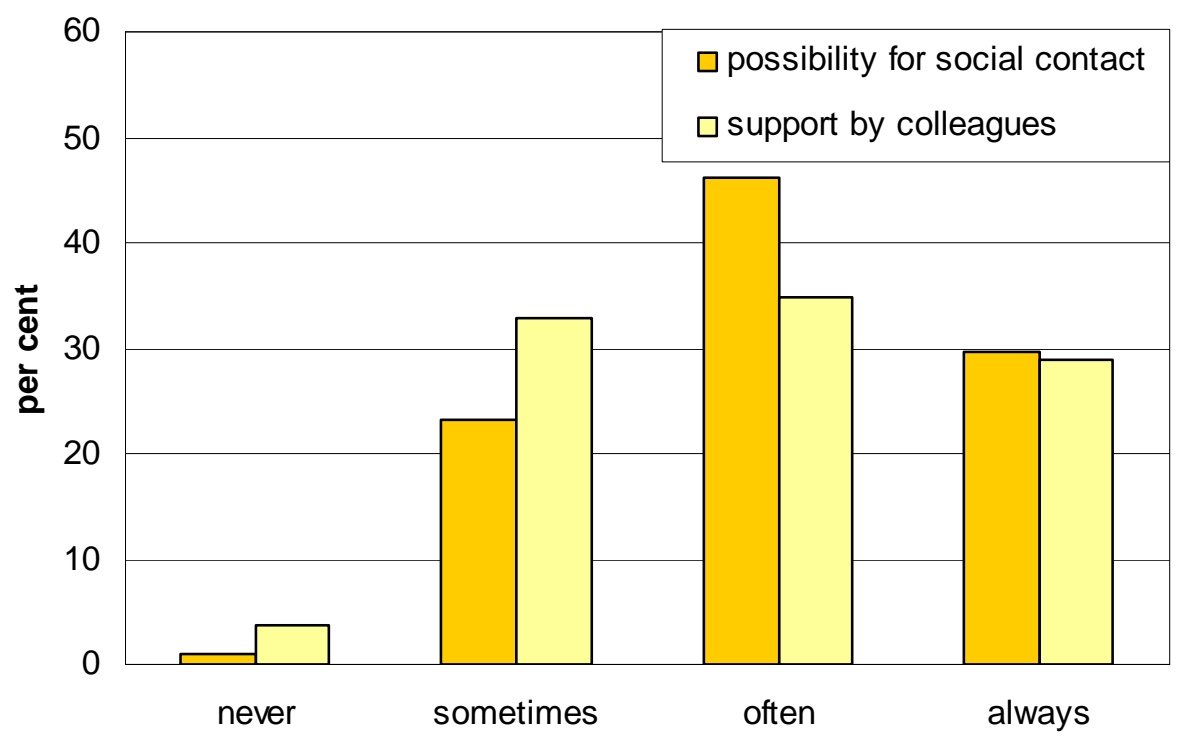

Figure 5: Frequency of how often participants have the possibility for social contact and receive support from colleagues if needed.

Older mobile teleworkers, that is, older than 45 years, reported significantly less support from colleagues than did younger mobile teleworkers $(p<.05)$.

Variance analysis shows that those who receive more support from colleagues have significantly less back and joint pain as well as fewer concentration problems (figure 6).

They can also complete tasks without interruption more often and generally have better possibilities for social contact. In addition they receive more acknowledgement and fewer contradictory instructions. 


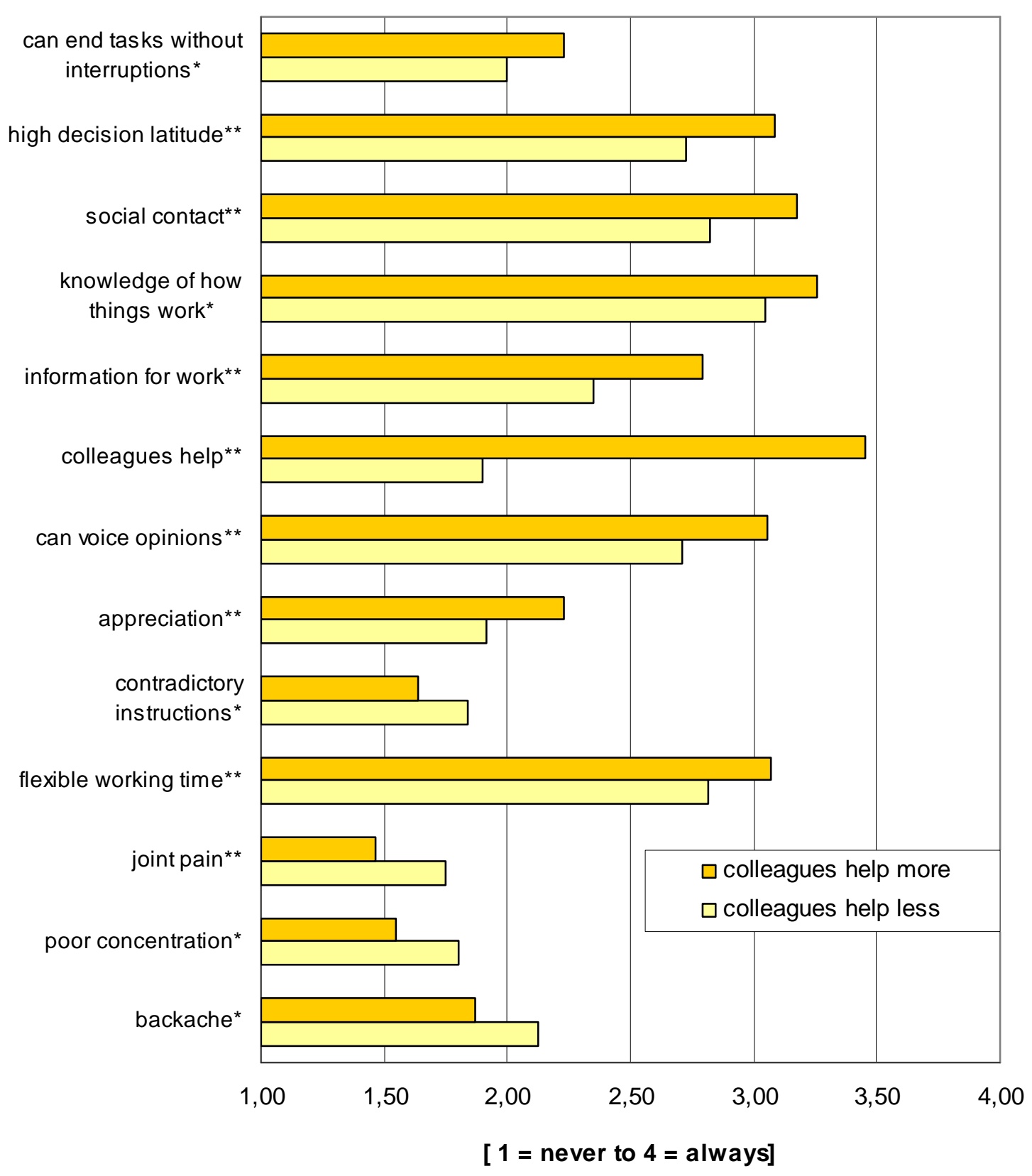

Figure 6: Mean of items with significant differences depending on whether colleagues help often/always or never/sometimes $\left(*=p<.05 ;{ }^{* *}=p<.01\right)$.

Personal influences and societal conditions

Mobile telework places special demands on the employee. As mobile teleworkers mostly have to structure their work days and arrange appointments on their own the ability to self-organize is essential (figure 7). This is rated by about two-thirds as good. Approximately a third rate this situation as neither good nor bad or bad. 


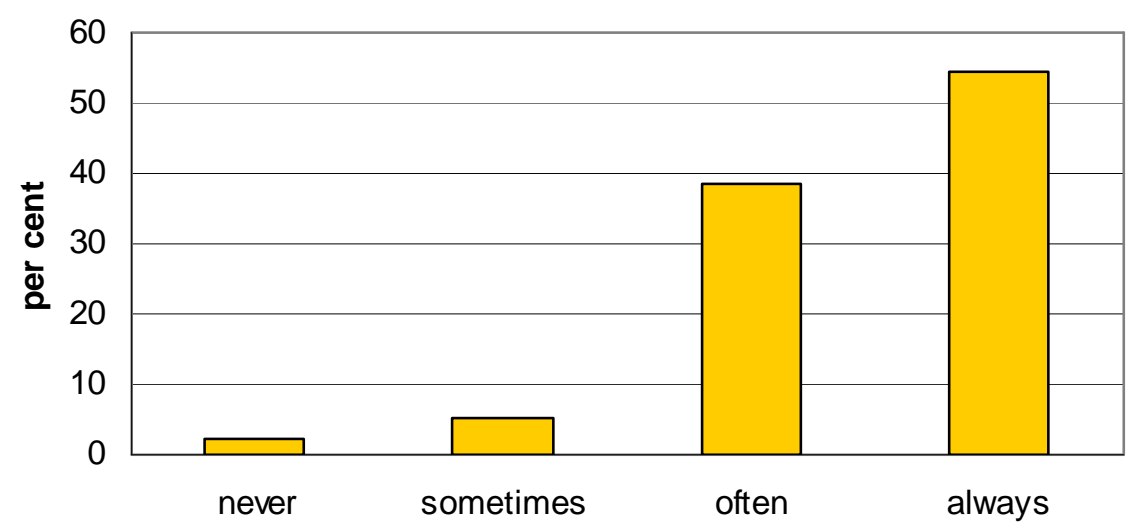

Figure 7: Frequency of how often participants state that the demand to organise work is high.

Respondents were asked to estimate if their job position is secure. Three quarters of them replied that their position is secure. Over $20 \%$ of respondents believe that this is not the case. Variance analysis, which separated people who evaluate their position as secure from those who rate it as unsafe, shows that those with job insecurity have significantly more:

- eye complaints,

- back pain and

- neck problems.

And that these people:

- have less flexibility in organising their work time,

- have less of a say in matters,

- receive less information that is important for their work and

- have less room to make decisions

(significance for information for work $p<.05$, all others each $p<.01$ ).

Differences as a function of device number and travel days

The frequency of psychological stress shows hardly any correlation to the number of devices. Variance analysis indicates that people who use three or more devices have their work interrupted more often by telephone calls and emails and that they regularly work on weekdays and bank holidays (each $p<.05$ ). Those who are on the road for more than three days show significant differences to those who are on the road for up to three days. They are shown in figure 8. The data shows that the situation for those who work a lot mobile is more unfavourable than for those who are less on the road. 


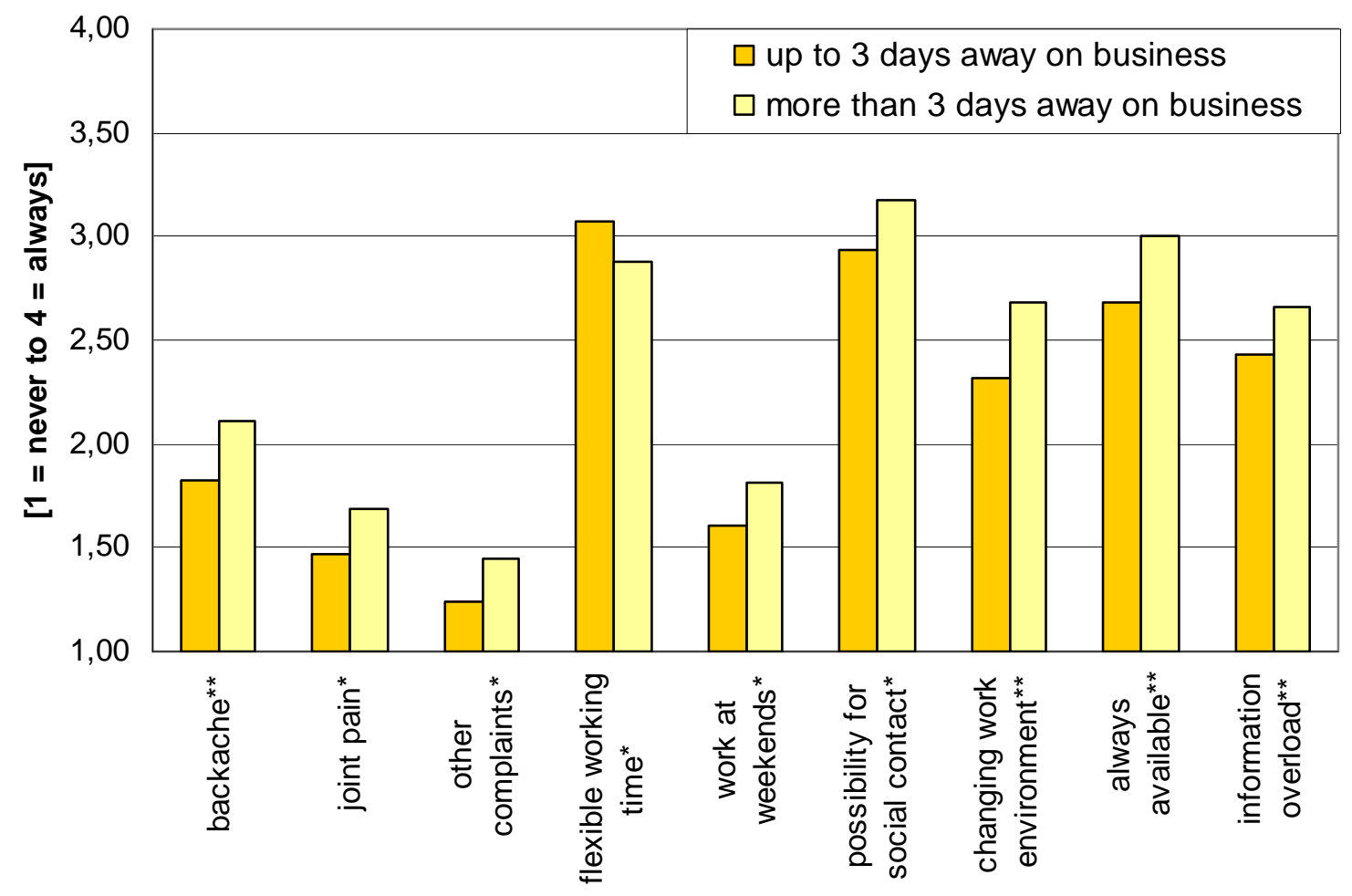

Figure 8: Mean of items with significant differences depending on whether participants are up to three days away on business or more $\left(^{*}=p<.05 ;^{* *}=p<.011\right.$.

Differences as a function of external and internal influence

The respondents were also asked if they feel that mobile IT controls them or rather they control it. Figure 9 shows that after variance analysis there are significant differences between the two groups. Through this comparison it can be seen that those who feel in control have fewer health problems as well as less pressure in terms of appointments and time. They also can allocate their time more flexibly and don't have to work as often at the weekend. They have a better understanding of how their devices work, have more room for decision making and are less inundated with information. 
can end tasks without interruptions**

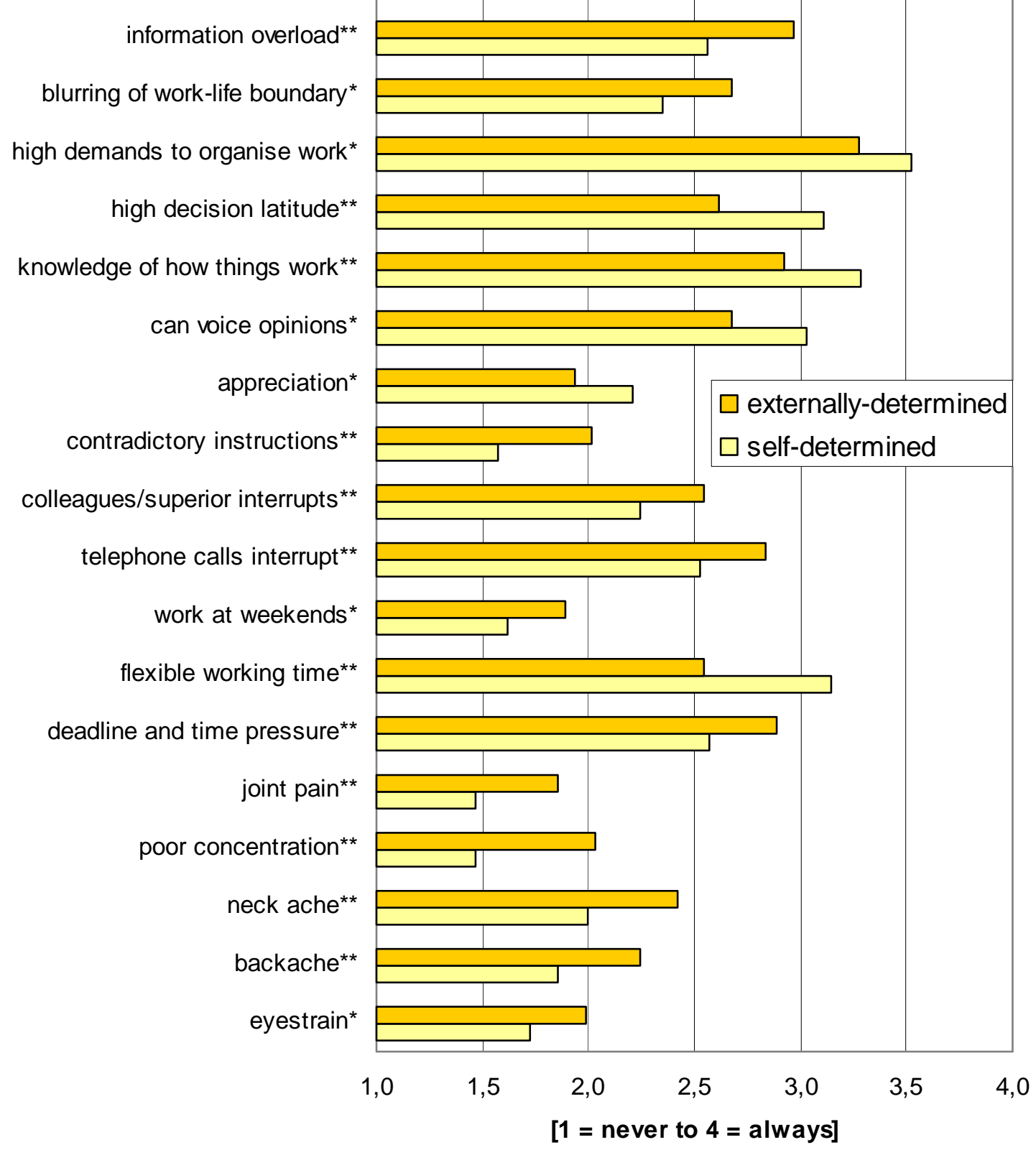

Figure 9: Mean of items with significant differences depending on whether participants feel externally-determined or self-determined when using mobile devices $1^{*}=$ $p<.05 ; * *=p<.011$.

\section{Discussion}

The results support many of the existing findings. Additionally they provide new aspects which are important for further studies and for prevention work.

The results from an ergonomic point of view show clearly that there is a need to improve work equipment. It can be assumed that this will reduce physical complaints. 
Regarding work organisation the data show that the majority of participants can flexibly organize their work and have a high decision-making latitude. Both aspects are evaluated quite positively. Other findings also show that flexibility and decisionmaking latitude are generally assessed positively and that they are associated with higher job satisfaction. However, too much flexibility may lead to excessive demands in self organisation and to longer working hours. More research is needed to determine what level of flexibility is appropriate. Interaction with tasks and skills has to be considered in this research. The existence of communication barriers that was found in other studies (Siegel et al., 1986, Sproull \& Kiesler, 1987, Ocker et al.,1996) was also found in this survey. The negative evaluation of this situation is in accordance with existing literature. Unexpectedly, availability and blurring of boundaries between work and private life is judged as negative by only one third of the participants. It may be of interest to investigate under which working and private conditions people evaluate availability and blurring more or less positive or negative respectively.

Regarding social relations at work the survey shows that the majority of participants have possibilities for social interactions and receive support from colleagues. This finding partially contradicts existing research which shows that mobile workers lack social contact and support (Mulki et al., 2008, Mann \& Holdsworth, 2003). It must be taken into consideration, however, that the latter findings mostly refer to homebased teleworkers. Regarding the relationship between social support and health the study confirms results of other research that found a negative correlation between social support and physical as well as mental complaints (Dormann \& Zapf, 1999).

The data show that the demand for self organization is high. Therefore, the general recommendation to train self organization skills which can be found in the literature should be put into practice. The correlation between job security and physical and mental complaints should also be investigated further. In accordance with other studies (Sverke, Hellgren \& Näswall, 2002, Barling \& Kelloway, 1996) the present data show that people who have an insecure job suffer from more physical and mental complaints. However, the direction of this relationship does not seem to be clear.

As expected, the situation is worse for those people who work mobile for more than three days per week than for those who work less mobile.

It also appears important that mobile workers have the feeling that they are in control of their devices and not the other way around. Those who consider the use of IT 
devices as self-determined also rate many other aspects more positive. Possibly this feeling depends on whether the person feels confident using the device. That means that intensive training can have a positive effect not only on handling the device but also many other aspects.

The results of the survey offer starting points for prevention which must be further clarified. For example, can devices and working equipment be significantly improved in ergonomic terms?

It also seems important to train self-organisation skills so that this demand does not lead to stress. Possibilities for social contact through the appropriate channels, for example, regular work update meetings should be implemented. In addition, work should be organised so that there are times when the employee does not have to be on-call.

For a more in-depth assessment of the situation for mobile workers there should be further investigation. Additional insights could provide a difference in mobile working conditions as individual requirements such as availability or self-organisation vary greatly between mobile workers.

\section{References}

Barling, J., \& Kelloway, E. K. (1996). Job insecurity and health: The moderating role of workplace control. Stress Medicine, 12, 253-259.

Brandt, C., \& Brandl, K.-H. (2008). Von der Telearbeit zur mobilen Arbeit. Computer und Arbeit, 3, 15-20.

Burchell, B., Fagan, C., O'Brien, C., \& Smith, M., (2007). Working conditions in the European Union: the gender perspective. Research Report by the European Foundation for the Improvement of Living and Working Conditions.

Charness, N. (2006). Work, Older Workers and Technology. Generations, 30, 25-30.

Dormann, C., \& Zapf, D. (1999). Social support, social stressors at work and depression: Testing for moderating effects with structural equations in a 3-wave longitudinal study. Journal of Applied Psychology, 84, 874-884. 
European Agency for Safety and Health at Work (2007). Expert forecast on emerging psychosocial risks related to occupational safety and health. Research Report.

European Commission (2001). eWork 2002 - Status Report on New Ways to Work in the Knowledge Society. European Commission, Information Society Directorate-General (ftp://ftp.cordis.lu/pub/ist/docs/ka2/ework2002en.pdf )

European Foundation for the Improvement of Living Conditions (2007). Fourth European Working Conditions Survey.

http://www.eurofound.europa.eu/pubdocs/2006/98/en/2/ef0698en.pdf

Gajendran R. S., \& Harrison D. A. (2007). The Good, the Bad, and the Unknown About Telecommuting: Meta-Analysis of Psychological Mediators and Individual Consequences. Journal of Applied Psychology, 92,1524-1541.

Gareis, K., Lilischkis, S., \& Mentrup, A. (2006). Mapping the Mobile eWorkforce in Europe. In E. Andriessen \& M. Vartiainen (Eds): Mobile Virtual Work - A New Paradigm? (pp. 4570). Springer: Berlin.

Garrett, R.K., \& Danziger, J.N. (2007). Which Telework? Defining and Testing a Taxonomy of Technology-Mediated Work at a Distance. Social Science Computer Review, 25, 2747.

Goudswaard, A., \& de Nanteuil, M. (2000). Flexible Employment Policies and Working Conditions. European Foundation of Living and Working Conditions. Consolidated Report, Dublin.

Haddon, L., \& Brynin, M. (2005). The character of Telework and the characteristics of teleworkers. New Technology, Work and Employment, 20, 34-46.

Hill, E.J., Ferris, M., \& Märtinson, V. (2003). Does it matter where you work? A comparison of how three work venues (traditional office, virtual office, and home office) influence aspects of work and personal/ family life. Journal of Vocational Behavior, 63, 220-241.

Hill, E. J., Hawkins, A. J., Ferris, M., \& Weitzman, M. (2001). Finding an extra day a week: The positive effect of job flexibility on work and family life balance. Family Relations, 50 , 49-58.

Hill, E.J., Miller, B.C., Weiner, S.P., \& Colihan, J. (1998). Influences of the virtual office on aspects of work and work/life balance. Personnel Psychology, 51, 667-683. 
Hislop, D., \& Axtell, C. (2007). The neglect of spatial mobility in contemporary studies of work: the case of Telework. New Technology, Work and Employment, 22, 34-51.

Hörmann, S. (2000). Sind Telearbeiter anders? Psychosoziale und sozioökonomische Aspekte moderner Arbeitsverhältnisse. Frankfurt am Main: Lang.

Hurme, P. (2005). Mobile Communication and Work Practices in Knowledge-Based Organizations. An Interdisciplinary Journal on Humans in ICT Environments, 1, 101-108.

Illegems, V., Verbeke, A., \& S' Jegers, R. (2001). The organizational context of teleworking implementation. Technological Forecasting and Social Change, 68, 275-91.

Jones, F., \& Bright, J. (2001). Stress. Myth, Theory and Research. New Jersey: Prentice Hall.

Karasek, R.A., \& Theorell, T. (1990). Healthy work: stress, productivity and the reconstruction of work life. New York: Basic Books.

Kohn, M. (2006). Business Process Oriented Safety and Health at Mobile IT-supported Work. 28. International Congress on Occupational Health. 11-16 June 2006, Milano.

Mann, S., \& Holdsworth, L. (2003). The psychological impact of telework: stress, emotions and health. New Technology, Work and Employment, 18, 196-211.

Martens. M.F.J., Nijhuis, F.J.N., van Boxtel, M.P.J., \& Knottnerus, J.A (1999). Flexible work Schedules and Mental and Physical Health. A Study of a Working Population with nontraditional Working Hours. Journal of Organizational Behavior, 20, 35-46.

Mulki, J.P., Locander, W.B., Marshall, G.W., Harris, E.G., \& Hensek, J. (2008). Workplace Isolation, Salesperson Commitment, and Job Performance. Journal of Personell Selling and Management, 28, 67-78.

Ocker, R.J., Hiltz, S.R., Turoff, M., \& Fjermestad, J. (1996). The effects of distributed group support and process structuring on software requirements development teams. Journal of Management Information Systems, 12, 127-153.

Öhlin, B., Nilsson, P.M., Nilsson, J.-Å., \& Berglund G. (2004). Chronic psychosocial stress predicts long-term cardiovascular morbidity and mortality in middle-aged men. European Heart Journal, 25, 867-873. 
Richter, G., \& Schatte, M. (2005). Psychologische Bewertung von Arbeitsbedingungen Screening für Arbeitsplatzinhaber - BASA. Weiterentwicklung, Validierung und Software. Dortmund: Bundesanstalt für Arbeitsschutz und Arbeitsmedizin.

SIBIS (2002/2003). SIBIS ("Statistical Indicators Benchmarking the Information Society", IST-26276-SIBIS project), http://www.sibis-eu.org/

Siegrist, J. (1996). Soziale Krisen und Gesundheit (Social crisis and health). Göttigen: Hogrefe.

Siegel, J., Dubrovsky, V, Kiesler, S., \& McGuire, T. W. (1986). Group processes in computermediated communication. Organizational Behavior and Human Decision Processes, 37 , 157-187.

Sproull, L., \& Kiesler, S. (1987). Reducing social context cues: electronic mail in organization communication. Management Science, 32, 1432- 1512.

Sverke, M., Hellgren, J., \& Näswall, K. (2002). No security: A meta-analysis and review of job insecurity and its consequences. Journal of Occupational Health Psychology, 7, 242 264.

About the authors:

Dr. Hiltraut Paridon studied psychology at the Universities of Duisburg and Wuppertal in Germany. In 2000 she received her PhD at the University of Tuebingen. She works at the BGAG - Institute Work and Health of the German Social Accident Insurance as a researcher and trainer since 2000.

Marlen Hupke studied psychology at the Technical University of Dresden, Germany. From 2006 to 2008 she worked at the BGAG - Institute Work and Health of the German Social Accident Insurance as a researcher and trainer. She is currently participating in a PhD programm of the IfADo - Leibnitz Research Centre for Working Environment and Human Factors in Dortmund, Germany and the German Social Accident Insurance.

Address correspondence to Hiltraut Paridon, BGAG - Institut Arbeit und Gesundheit, Königsbruecker Landstr. 2, 01109 Dresden, Germany,

Email: hiltraut.paridon@dguv.de 